\title{
Coexistência entre Turdus leucomelas Vieillot, 1818 e Turdus rufiventris Vieillot, 1818 (Aves: Passeriformes) em um fragmento urbano de floresta com araucárias, Sul do Brasil
}

\author{
Huilquer Francisco Vogel ${ }^{1,4}$, Cláudio Henrique Zawadzki² \& Rafael Metri ${ }^{3}$ \\ ${ }^{1}$ Programa de Pós-graduação em Ciências Biológicas - Biologia Evolutiva, \\ Universidade Estadual do Centro-Oeste - UNICENTRO, \\ Rua Simeão Camargo Varela de Sá, 03, CEP 85040-080, Guarapuava, PR, Brasil \\ ${ }^{2}$ Departamento de Biologia, Núcleo de Pesquisas em Limnologia, Ictiologia e Aqüicultura, \\ Centro de Ciências Biológicas, Universidade Estadual de Maringá - UEM, \\ Av. Colombo, 5790, CEP 87020-900, Maringá, PR, Brasil \\ ${ }^{3}$ Departamento de Ciências Biológicas, Universidade Estadual do Paraná - UNESPAR, \\ Câmpus FAFIPAR, Rua Comendador Correia Junior, 117, CEP 83203-280, Paranaguá, PR, Brasil \\ ${ }^{4}$ Autor para correspondência: Huilquer Francisco Vogel, e-mail: huilquer@yahoo.com.br
}

VOGEL, H.F., ZAWADZKI, C.H. \& METRI, R. Coexistence between Turdus leucomelas Vieillot, 1818 and Turdus rufiventris Vieillot, 1818 (Aves: Passeriformes) in an urban remnant of Araucária tree Forest, Southern Brazil. Biota Neotrop. 11(3): http://www.biotaneotropica.org.br/v11n3/en/abstract?article+bn00411032011

\begin{abstract}
We investigated the strategies which make possible the coexistence of two congeneric and relatively similar species that share habitat (Turdus leucomelas and Turdus rufiventris) in an urban forest fragment with araucárias. The parameters applied were average abundance, forest stratum used by birds, forest environments, morphological aspects, and diet between the species. These parameters were assessed through samplings with mist nets in the understory, verification of abundance using transects, and acquisition of regurgitation. The species showed similar patterns of occurrence in the surveyed environments - exposed border, transition, and inner forest. There was a morphological overlap of 98.67 (Bray-Curtis index), andt a test of canonical variables $\left(F_{6,88}=25.39\right.$; $p<0.01)$ pointed significant difference for a set of seven morphological variables. Although there is certain similarity between species, $T$. rufiventris showed higher extreme values and higher morphological variation. The overlap of trophic niche was elevated $(\mathrm{O} j k=0.76)$ and the species were considered as generalists, with higher extent of trophic niche for $T$. rufiventris. A competitive exclusion based on feeding is not quite evident. Yet, the consumed items diverged when analyzed for presence/absence, the minimum of morphological evidence and variation on the consumed resources may partially explain the coexistence. Segregation between environments and occupied forest strata was not clearly demonstrated, despite detectable when regarding interior and border of the forest fragment.
\end{abstract}

Keywords: coexistence, Turdidae, urban forest fragment.

VOGEL, H.F., ZAWADZKI, C.H. \& METRI, R. Coexistência entre Turdus leucomelas Vieillot, 1818 e Turdus rufiventris Vieillot, 1818 (Aves: Passeriformes) em um fragmento urbano de floresta com araucárias, Sul do Brasil. Biota Neotrop. 11(3): http://www.biotaneotropica.org.br/v11n3/pt/abstract?article+bn00411032011

Resumo: Neste trabalho foram investigadas algumas das estratégias que tornam possíveis a coexistência de duas espécies sintópicas e congenéricas (Turdus leucomelas e Turdus rufiventris), em um fragmento urbano de floresta com araucárias. Os parâmetros amostrados foram a abundância média, estrato florestal utilizado pelas aves, ambientes florestais, aspectos morfológicos, e a dieta. Tais parâmetros foram obtidos através de capturas com redes ornitológicas no sub-bosque, constatação da abundância através de transecções, e obtenção de regurgitos. Foi possível estimar que as espécies possuem padrões similares de ocorrência nos ambientes amostrados - borda exposta, transição e interior. Existe uma sobreposição morfológica de 98,67 (índice de Bray-Curtis) sendo que um teste de variáveis canônicas $\left(F_{6,88}=25,39 ; p<0,01\right)$ demonstrou uma diferença significativa para um conjunto de sete variáveis morfológicas. Apesar de existir certa semelhança entre as espécies, T. rufiventris apresentou maiores valores extremos e maior variação morfológica. A sobreposição de nicho trófico foi elevada $(\mathrm{O} j k=0,76)$ e as espécies se apresentaram generalistas com amplitude de nicho trófico superior para T. rufiventris. Não é muito evidente uma exclusão competitiva baseada na alimentação, no entanto os itens consumidos divergiram quando analisados por presença/ausência. Desta forma, o mínimo de divergência morfológica e variação nos recursos consumidos podem explicar parcialmente a coexistência, já que a segregação entre ambientes e estrato florestal ocupado não foi claramente observada, apesar de perceptível em relação ao interior e borda do fragmento florestal. Palavras-chave: coexistência, Turdidae, fragmento florestal urbano. 


\section{Introdução}

A família Turdidae Rafinesque, 1815 é um grupo de aves cosmopolitas com mais de 300 espécies. Dentre estudos envolvendo o gênero Turdus Gregórie et al. (2003) estudaram efeitos da predação sobre Turdus merula Linnaeus, 1758 na França, Hogstad (2004) estudou a estratégia de interação em Turdus pilaris Linnaeus, 1758 frente à ameaça de predadores mamíferos, Burfield \& Brooke (2005) constataram o declínio de T. torquatus Linnaeus, 1758 frente à substituição de paisagens naturais na Grã-Bretanha, entre outros. Estes estudos possuem os mais variáveis enfoques, uma vez que os turdídeos formam um grupo amplamente distribuído, onde cada região possui suas próprias espécies e, por se tratar de espécies abundantes em centros urbanos, acabam sendo utilizadas para testar modelos experimentais (Bonnevie 2005).

A origem evolutiva dos turdídeos está relacionada ao "velho mundo", de onde alcançaram as Américas através da região Neártica, migrando até a América do Sul. Alguns fósseis da Califórnia (EUA) datam de 20 milhões de anos (Sick 1997), enquanto fósseis de espécies ainda viventes como T. merula e T. iliacos Linnaeus, 1766 foram encontrados, respectivamente, em florestas folhosas e de coníferas em áreas temperadas de Kozarskat (Bulgária), durante o Pleistoceno, entre 11 e 1,8 milhões de anos (Boev 2001).

No Brasil, são registradas 13 espécies do gênero Turdus (Comitê... 2009), sendo que em sua maioria são aves silvícolas, podem estar representadas em uma mesma área por mais de uma espécie compartilhando habitat, portanto sintópicas (Sick 1997). Sigrist (2006) apontou este grupo como de espécies onívoras e generalistas, enquanto Reichard et al. (2001) consideram-nas frugívoras, contribuindo para a dispersão natural de espécies vegetais nativas ou exóticas através de fragmentos de florestas urbanas e periurbanas.

Turdus rufiventris Vieillot, 1818 e T. leucomelas Vieillot, 1818, são consideradas abundantes (Gasperin \& Pizo 2009) e com ampla distribuição no Brasil (Collar 2005). Possuem tamanhos corporais relativamente grandes em comparação com as demais espécies sintópicas e congenéricas (Sick 1997).

Em estudos de estrutura de comunidades de aves brasileiras, essas duas espécies apresentam índices elevados de abundância (Gasperin \& Pizo 2009) e também elevados índices de captura e recaptura através do uso de redes ornitológicas (Piratelli \& Pereira 2002) e igualmente abundantes em centros urbanos (Krügel \& Anjos 2000). São consideradas onívoras com ocorrência de itens vegetais e animais em sua dieta (Gasperin \& Pizo 2009), o que também foi constatado para outras espécies de turdídeos (Tomaz \& Alves 2007).

Além da onivoria, alguns estudos demonstram que espécies deste grupo, como T. rufiventris, interagem através de estratégias de bandos mistos, uma forma de maximizar o sucesso na procura de alimento, apresentando alteração da altura média de forrageamento quando integra tais bandos. Isto demonstra uma plasticidade em seu comportamento de forrageio para adequar-se à estratégia e dela obter vantagens (Machado 1999). Tal plasticidade pode conferir uma vantagem adaptativa frente a processos de fragmentação florestal e extinções locais.

De qualquer maneira, a coexistência de turdídeos congenéricos e de porte razoavelmente grande, de acordo com Sick (1997), deve envolver mecanismos ecológicos não tão facilmente distinguíveis. Embora os mecanismos de interação entre T. rufiventris e T. leucomelas não sejam claramente conhecidos, é fato que competição e predação são fatores fundamentais na restrição de coexistência entre espécies (Roughgarden \& Diamond 1986). Uma resposta evolutiva na competição entre duas espécies é a divergência morfológica, comportamental ou até mesmo no uso diferenciado de recursos alimentares ou espaciais (Krebs 1985).
Embora espécies congenéricas possam ser consideradas semelhantes, para MacArthur \& Levins (1967) deve haver um limite máximo na similaridade morfológica, que garantirá o uso de itens ligeiramente distintos (hipótese da similaridade limitante). Esta sutil distinção de recursos garantirá que na relação de espécies co-ocorrentes haja uma sobreposição de nichos, porém não total (Hutchinson 1959, Pianka 1982), gerando certa redução na amplitude de nichos potenciais e estreitamento no nicho realizado (Pianka 1967). No entanto, a competição só será atuante caso ocorra sobreposição de recurso e caso este seja limitante (Putmam 1996).

Aspectos morfológicos como a forma estão associados com a ecologia da espécie, podendo estar correlacionados com a maneira de explorar recursos alimentares, com o forrageamento e ocupação do ambiente (Hespenheide 1973, Schoener 1974). Assim sendo, características relacionadas com alimentação deveriam exibir uma diferença mínima compatível (Hutchinson 1959), e qualquer diferença em espécies simpátricas poderia ser interpretada como consequência evolutiva de seleção favorecendo divergência de caracteres com um mínimo de divergência morfológica (Lossos 2000).

Partindo desta desta base teórica, este trabalho pretende: a) comparar parâmetros morfológicos entre T. rufiventris e T. leucomelas a fim de testar o quanto as espécies são semelhantes, ou divergem em um mínimo possível; e b) descrever quais mecanismos tornam possível a coexistência entre T. rufiventris e T. leucomelas, tendo como parâmetros a partilha de espaço, análise de sobreposição e composição de suas dietas, e picos de atividade, já que estas, em muitas situações, são consideradas espécies potencialmente competidoras.

\section{Material e Métodos}

\section{1. Área de estudo}

O remanescente florestal estudado está localizado no Parque Municipal das Araucárias (PMA) localizado às margens da BR 277, Km 343, Município de Guarapuava, região Centro-Sul do Estado do Paraná. O remanescente estudado possui 104 ha, cerca de 41 ha cobertos por Floresta Ombrófila Mista, com altitude em torno dos 1070 m (Figura 1). O Parque encontra-se delimitado na parte norte pelo Rio Xarquinho e vegetação rala que faz transição com uma área de matriz agrícola. Ao sul e leste há áreas antropizadas dentro do PMA, e nas adjacências uma matriz urbana (Cordeiro \& Rodrigues 2007). A área de estudo abordada nesta pesquisa possui área aproximada de 20 ha.

O clima da região, segundo a classificação de Köppen, é do tipo $C f b$, sem estação seca definida. A temperatura média do ar do mês mais quente é próxima a $20,9^{\circ} \mathrm{C}$ e a média do mês mais frio $8,4{ }^{\circ} \mathrm{C}$. Os índices de precipitação médios apontam $93,9 \mathrm{~mm}$ para o mês mais seco e 202,6 mm para o mais chuvoso, com um mínimo de oito e máximo de 16 dias por mês de chuva (Cordeiro \& Rodrigues 2007).

Cinco espécies de plantas (a araucária Araucária angustifolia, a guabiroba Campomanesia xanthocarpa, a guaçatunga Casearia decandra, a pimenteira Capsicodendron dinisii e a fruta-do-pombo Allophylus edulis) apresentam juntas cerca de $64 \%$ de valor de importância (VI\%) na estrutura do remanescente florestal, onde também estão presentes espécies exóticas da flora, representando $11,7 \%$ da riqueza total de espécies arbóreas (Cordeiro \& Rodrigues 2005). Dentre as espécies com potencial de dispersão zoocórica estão a uva-do-Japão Hovenia dulcis e o alfeneiro Ligustrum lucidum, sendo que está última espécie já passa a constituir a estrutura horizontal da floresta, obtendo o $29^{\circ}$ lugar no índice de valor de importância (Cordeiro \& Rodrigues 2007).

\section{Procedimentos e obtenção de dados}

O trabalho de campo foi realizado entre meados de Dez/2008 a Nov/2009, início do verão, com término no final da primavera. Para 
o estudo da partilha de habitat, foram efetuadas três transecções adaptadas do proposto por Bibby et al. (1993), semelhante ao utilizado por Zaca (2000). Cada transecção foi de aproximadamente $380 \mathrm{~m}$, sem o uso de pontos amostrais, uma vez que não foram efetivos para a constatação das espécies abordadas neste estudo devido a dificuldade de estabelecer contato visual com os espécimes no período não reprodutivo.

A área de estudo foi subdividida em três categorias de ambientes: borda exposta (este ambiente se caracteriza por uma transição abrupta entre o habitat florestal e o ambiente aberto): pronuciando-se até uma largura aproximada de $5 \mathrm{~m}$ a partir da área aberta; borda intermediária: inicia-se imadiatamente após terminar a área categorizada como borda exposta até atproximadamente $35 \mathrm{~m}$ em direção ao interior do fragmento. A terceira categoria, denominada de interior florestal, contempla a porção do fragmento florestal posterior a 35 m em relação à borda, pois de acordo com Rodrigues (1998), o efeito de borda é mais pronunciável nos 35 primeiros metros.

As três transecções foram percorridas duas vezes por mês partindo de pontos predeterminados (Figura 1), onde LT1 são pontos de início e término da transecção referente à borda exposta; LT2 refere-se aos pontos de início e fim da transecção equivalente à borda intermediária e por sua vez, LT3 consta como início e término do transecto no interior florestal. Para a determinação correta de inicio e término de cada transecto, foram distribuídas etiquetas de orientação no local de início e termino de cada transecção. Características da vegetação de cada ambiente contemplado, podem ser melhor visualizadas na Figura 2. A ordem das transecções e sentido de início foram sorteadas e efetuada nos seguintes intervalos de tempo: 05h1506h45; 07h15-08h45; 09h15-10h45; 11h15-12h45; 13h15-14h45; 15h15-16h45 e 17h15-18h45. A velocidade de deslocamento foi de aproximadamente $2,5 \mathrm{~km} / \mathrm{h}$ obtida através de GPS-Garmim 12. As três transecções foram amostradas igualmente, totalizando 24 amostragens anuais por transecção, seis por estação, com duração $\approx 15 \mathrm{~min} /$ transecção.

Ao percorrer as transecções foram anotados somente os registros visuais de turdídeos, buscando estimar a altura em que o animal se encontrava em relação ao solo com precisão de $0,5 \mathrm{~m}$ e o tipo de ambiente: borda exposta, borda transição e interior.

Para amostragem da dieta e tomada de parâmetros biométricos das aves, foram realizadas capturas no sub-bosque utilizando seis redes de neblina, tratando-se de três redes malha $35 \mathrm{~mm}$ e outras três $20 \mathrm{~mm}$, com seis metros de comprimento por três de altura dispostas entre 50 a $150 \mathrm{~cm}$ do nível do solo. As redes foram armadas em campo desde às $07 \mathrm{~h} 00$ onde permaneciam até o entardecer, quando cessou a atividade das aves por volta das $19 \mathrm{~h} 00$. A frequência das armadilhagens foi de quatro amostragens mensais $12 \mathrm{~h} /$ campo

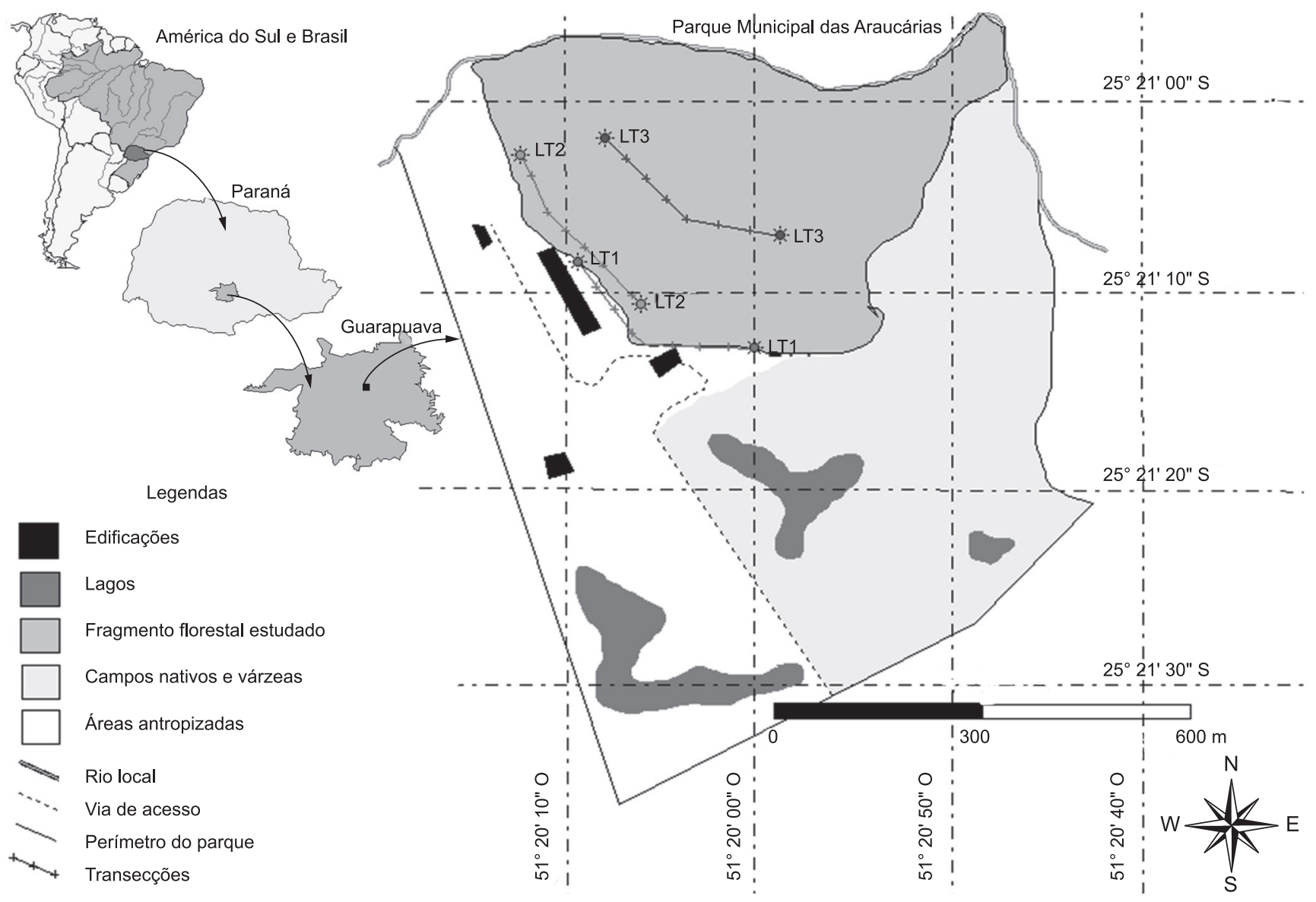

Figura 1. Localização do Parque Municipal das Araucárias (PMA), Guarapuava, Estado do Paraná. Em detalhe (linhas pontilhadas LT1, LT2 e LT3) transecções percorridas no trabalho de campo.

Figure 1. Location of the Parque Municipal das Araucárias (PMA), Guarapuava, Paraná State. In detail (dashed lines LT1, LT2 and LT3) transects in fieldwork. 
(48 h/campo mês, somando 144 h por estação, totalizando 576 h/ campo (3456 h/rede), com um esforço amostral $(E)$ calculado a partir de Straube \& Bianconi (2003) de $E=1872$ h.m² por estação ( $E=7488$ h.m ${ }^{2}$ durante o ano amostral). A escolha do local de instalação das redes foi realizada a partir de uma análise prévia em um dia anterior, escolhendo locais de maior atividade das espécies na tentativa de maximizar as capturas.

Para obtenção de regurgitos foram utilizadas aves capturadas após as $08 \mathrm{~h} 00$. Portanto, com tempo de forrageio antes do procedimento, já que logo no início do estudo foi constatado que os espécimes capturados antes deste horário não regurgitavam, aumentando assim o estresse e chance de óbito. Os indivíduos foram identificados, acondicionados em sacos de algodão, pesados e medidos, obtendo-se as seguintes medidas: comprimento da cauda, tarso esquerdo e direito, asa esquerda e direita, comprimento do bico, comprimento da narina à ponta do bico, altura do bico em relação à base, largura do bico, comprimento total da ave e massa corpórea. Tais dados foram obtidos através de paquímetro digital (em $\mathrm{mm}$ ) e balança analógica com precisão de $0,1 \mathrm{~g}$, sendo que os parâmetros mensuráveis unilaterais foram padronizados do lado direito das aves evitando efeitos de assimetria, e as medidas foram realizadas com base em Sick (1997) e Auricchio (2001). Os individuos eram capturados e classificados entre adultos, filhotes e juvenis, de acordo com a textura do tarso, dureza das unhas, plumagem e calcificação cranial (Centro... 1994, Gonçalves \& Fontana 2009). Apenas individuos adultos foram considerados para as análises biométricas. Inviduos que apresentassem mudas em uma determinada captura só foram considerados no caso de recaptura sob novas aferições biométricas.

As aves foram marcadas com anilha metálica (cedidas pelo CEMAVE/SNA, ICMBio). Através dos dados provenientes das capturas foi possível projetar o número de capturas por intervalo de hora, como um possível pico de atividade das espécies. Para tal, foi usado o registro de 62 capturas de T. rufiventris e 58 de T. leucomelas com o objetivo de constatar uma eventual distinção de picos de atividade, o que poderia ser considerada como hipótese para coexistência. Foram utilizados nesta análise, apenas registros de capturas e recapturas, pois estima-se que as redes, permaneceram por intervalos ininterruptos de tempo em campo, amostrando com maior precisão em relação a variação no padrão de atividade dos espécimes em questão. Em seguida, as aves foram induzidas a regurgitar através da administração de tártaro emético (autorização $n^{\circ}$ 16053-1/CEMAVE/SNA) (solução de tartarato de antimônio e potássio, $1,5 \%$ de solução/ $0,8 \mathrm{~mL}$ por $100 \mathrm{~g}$ de peso, aquecida entre 30 e $40^{\circ} \mathrm{C}$ ), por via oral, com uma seringa de $1 \mathrm{~mL}$ e um escalpe de soro (Robinson \& Holmes 1982, Poulin et al. 1994, Mestre 2002).

Os indivíduos foram colocados individualmente em um recipiente plástico com tampa de tecido de algodão para permitir a respiração, permaneciam 30 minutos e eram libertados, tendo regurgitado ou não. Das aves capturadas antes das 08:00h da manhã só foram obtidos parâmetros biométricos. Sempre que possível, foi estimado o intervalo de hora em que o animal foi capturado. Os regurgitos foram armazenados em frascos plásticos, etiquetados e refrigerados a $-5^{\circ} \mathrm{C}$ para futura triagem. Posteriormente, as amostras foram submetidas à estufa a $60^{\circ} \mathrm{C}$ por 12 horas, triadas, separadas em itens animais e vegetais. As sementes foram identificadas com base em uma coleção de referência de sementes da reserva construída durante o estudo a partir da flora local. Dois registros, evidências da folivoria pela espécie, tiveram as nervuras das folhas comparadas com os registros já identificados dos outros ítens alimentares de origem alimentar vegetal.

\section{Análise dos dados}

Para testar a possível variação entre dados biométricos, primeiramente os parâmetros avaliados tiveram sua normalidade e homocedasticidade checadas e posteriormente foram submetidos ao teste $t$ de student entre as espécies. Uma análise de dissimilaridade de Bray-Curtis foi efetuada com base no conjunto de médias das variáveis obtidas, checando o nível de sobreposição morfológica. Posteriormente, todos os dados morfométricos lineares avaliados (considerando apenas um por medida pareada) em conjunto, após logaritimizadas (para atingir lineariedade), foram submetidos a uma análise multivariada de variáveis canônicas através do software PAST (Hammer et al. 2003), opção MANOVA/CVA. Este teste teve por objetivo checar se no conjunto total de variáveis, houve variação de forma entre as espécies e demonstrar quais caracteres têm maior participação na variação.

Os caracteres morfológicos relacionados com o bico das espécies foram também analisados em separado, posteriormente, por meio de uma análise de componentes principais (ACP), principalmente por serem medidas complementares, que refletem como o organismo irá explorar o nicho alimentar.

Para checar se a ocupação dos ambientes variou entre estações, ou se as espécies divergiram estatisticamente na abundância média por ambiente e estação, foi realizado o teste não paramétrico de Kruskal-Wallis (teste " $H$ ”), análogo à análise de variância. Adicionalmente, efetuou-se uma correlação pareada de Speerman relacionando a média de abundância entre as duas espécies nos ambientes amostrados em relação a cada estação e ranqueadas a partir da maior abundância da espécie mais abundante.

Os dados provenientes da altura média dos registros das espécies foram analisados através de estatística descritiva, onde a escala de análise foram dados anuais, e serviram para efetuar um teste de Kruskal-Wallis, na tentativa de constatar se as espécies divergem na altura média do estrato florestal freqüentado.

Tratando-se de recursos alimentares, com o objetivo de comparação de dietas, a amplitude de nicho foi obtida através do índice de Levins (1968): $B=1 / \Sigma \mathrm{pi}^{2}$, onde, $B$ é a amplitude do nicho
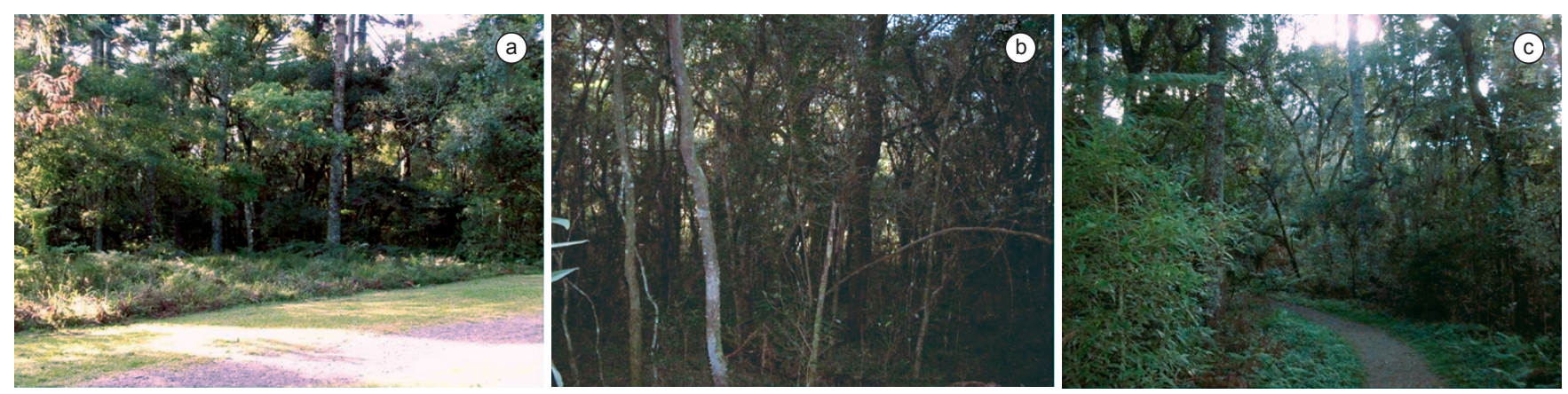

Figura 2. Ambientes amostrados: a) borda exposta; b) borda transição; e c) interior do fragmento florestal amostrado.

Figure 2. Study sites: a) exposed edge; b) transition edge; and c) inside the sampled forest remnant. 
trófico da espécie; $i$ é a categoria do recurso utilizado; $p$ é proporção da categoria $i$ utilizada por essa espécie. Para tal, foi elaborada uma matriz de recursos alimentares com base nas espécies vegetais de frutos (cada espécie como categoria) e duas categorias mais gerais: invertebrados Arthropoda e demais invertebrados, como Mollusca (Gastropoda) e Anellida.

A sobreposição de nicho foi estimada baseando-se no método de Pianka (1973). Os cálculos foram efetuados com o auxílio do software EcoSim 7.0 (Gotelli \& Entsminger 2004), utilizando-se valores de proporção de volume dos recursos alimentares consumidos pelos indivíduos analisados. Para o cálculo da similaridade trófica foi utilizado o índice simplificado de Morisita $(\mathrm{CH})$ (Horn 1966, Krebs 1989). Este índice está matematicamente relacionado ao índice de Shannon, no entanto, difere por dar maior peso à abundância (May 1975). Adicionalmente, foi realizada uma análise de dissimilaridade entre as dietas baseada na presença ou ausência de recursos alimentares, objetivando averiguar se, quanto aos itens utilizados, a dieta diferia. Para tal análise foi usado o índice de dissimilaridade de Bray-Curtis.

\section{Resultados}

Foram capturados 57 indivíduos de T. rufiventris (com cinco recapturas) (7,61/1000 h.m²) e 51 de $T$. leucomelas (sete recapturas) $\left(6,81 / 1000\right.$ h.m $\left.{ }^{2}\right)$. A estação em que houve mais capturas de T. rufiventris e T. leucomelas foi o outono com 20 e 25 indivíduos, respectivamente; sendo a primavera a estação menos abundante, com nove e quatro indivíduos capturados, respectivamente (Figura 3a). A correlação entre a abundância das espécies em cada mês demonstrou tendencia a variar de modo similar $(r=0,77 ; p>0,05)$.

Quanto aos picos de atividades das espécies, houve um pico mais representativo observado a partir das 16:00 h (Figura 3b). O único
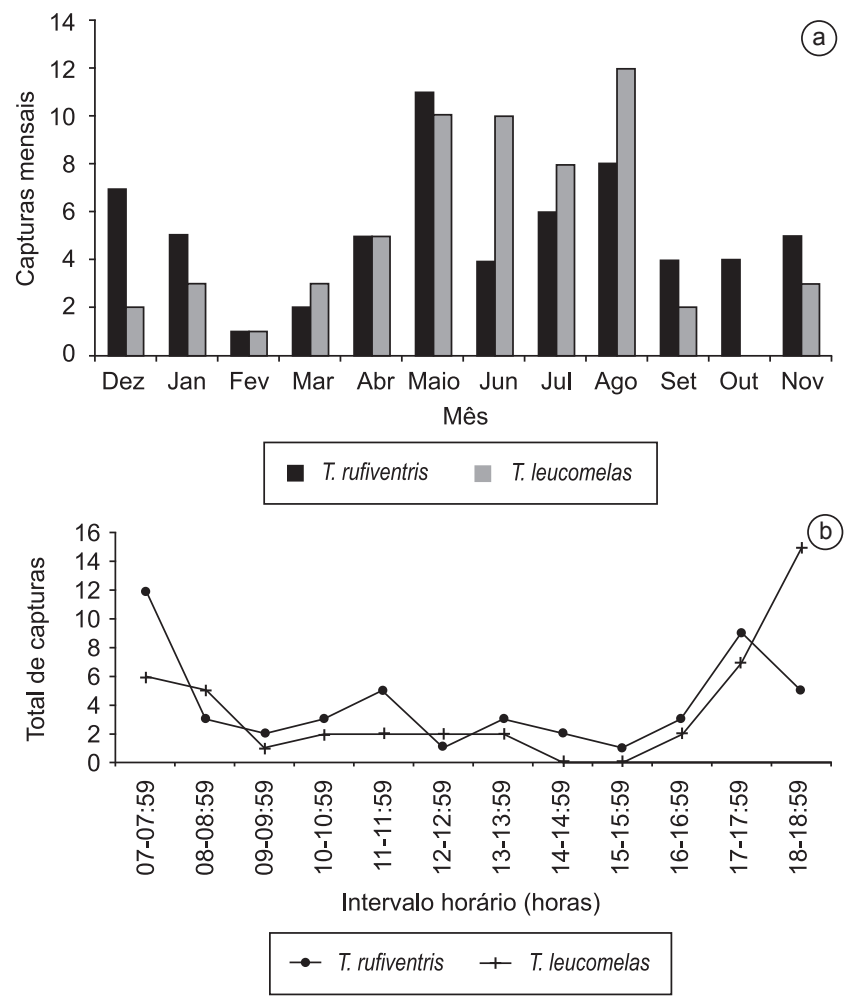

Figura 3. Abundância mensal (a) e picos de captura por intervalo horário (b) de Turdus rufiventris e T. leucomelas.

Figure 3. Monthly abundance (a) and peak of captures per time interval (b) of Turdus rufiventris and T. leucomelas. intervalo de horário em que não houve capturas foi entre $15 \mathrm{~h} 00$ e $15 \mathrm{~h} 59$ para $T$. rufiventris e no intervalo de $14 \mathrm{~h} 00$ a $14 \mathrm{~h} 59$ para T. leucomelas. Houve um pico de atividade constatado entre $07 \mathrm{~h} 00 \mathrm{e}$ 07h59 para T. rufiventris. Ao longo do dia, existiram pequenos picos sincrônicos de atividade, com menos de cinco capturas por intervalo de hora, porém, mais concentrada próximo ao entardecer.

Dentre as características morfológicas avaliadas entre as espécies, não houve diferença para a medida de massa. No entanto, para o comprimento total, tamanho dos bicos, comprimento do tarso (direito), comprimento da asa (direita) e finalmente cauda, houve divergências estatísticas conforme indicado na Tabela 1.

A análise de sobreposição das médias de variáveis morfológicas permitiu constatar uma sobreposição morfológica de 98,67 (índice de Bray-Curtis).

O resultado da análise de variáveis canônicas demonstrou uma diferença estatística para o conjunto de caracteres avaliados $\left(F_{6,88}=25,39 ; p<0,01\right)$. Houve separação entre o conjunto de variáveis em relação ao eixo 1 (Figura 4).

A análise de componentes principais, apenas com as variáveis referentes ao bico das aves, demonstrou que os três primeiros componentes principais obtidos a partir da correlação das quatro variáveis originais explicam juntos $90,9 \%$ da variação observada, sendo o componente 1 responsável por $45 \%$ do total e o componente 2 responsável por quase $24 \%$ (Tabela 2). O componente principal 1 relacionou-se às variáveis de tamanho do bico, especialmente ao comprimento total. O componente principal 2 foi fortemente relacionado à largura do bico e o componente 3 , à altura do bico (Tabela 2).

De maneira geral, os componentes avaliados em relação ao bico se mostraram fracamente correlacionados nas espécies estudadas. Com relação aos componentes do bico relacionados com a forma, foi constatada uma diferença morfológica apenas para o comprimento narina bico $t_{(99)}=9,40 ; p<0,05$. A largura do bico na base e a altura do bico em relação à base não variaram $t_{(99)}=2,034 p>0,05 \mathrm{e}$ $t_{(99)}=0,13 p>0,05$.

A partir dos dados de abundância obtidos das transecções realizadas, não houve um padrão que permita inferir que exista um ambiente entre borda, transição ou interior, que possa ser mais utilizado pelas espécies entre as estações do ano, sendo que os resultados do teste de Kruskal-Wallis foram para o verão, $H=4,51$, para o outono, $H=1,44$, para o inverno, $H=0,22$ e para a primavera, $H=3,21$ (em todos os casos não houve diferença significativa).

Embora a abundância média de T. rufiventris por ambiente e estação seja visualmente maior do que a de T. leucomelas (Figura 5), a diferença não foi estatisticamente significante, com valores de teste variando entre $H=0,10 p>0,05$ e $H=5,06 p \geq 0,05$. A abundância das espécies também não divergiu estatisticamente por ambiente e estação.

A análise da estratificação florestal entre as espécies a partir de 449 registros visuais de T. rufiventris e 287 de T. leucomelas permitiu inferir que as espécies ocupam um estrato florestal situado entre 0 a $12 \mathrm{~m}$ para $T$. rufiventris, e variando de 0 a $15 \mathrm{~m}$ de altura para T. leucomelas. Na distribuição dos dados, observa-se que entre as espécies e ambientes, os dados estão contidos dentro do primeiro quartil (25\%), correspondendo à uma altura 0 m (à exceção de T. leucomelas na borda florestal), o que demonstra a intensa utilização do solo pelas aves, sendo que $75 \%$ dos dados correspondem a uma altura igual ou inferior a $4 \mathrm{~m}$ (à exceção de T. leucomelas no interior florestal) (Tabela 3). Os maiores coeficientes de variação em relação ao estrato florestal frequentado foram sempre superiores a 100\% para T. rufiventris, e inferiores a $100 \%$ para T. leucomelas.

Em uma comparação entre as espécies e ambientes, foi constatada uma variação interespecífica na ocupação da altura média do estrato 
florestal no ambiente borda, havendo certa segregação neste ambiente, obtendo-se valores de teste de Kruskal-Wallis: $H=9,3(p<0,05)$, com estrato ocupado próximo de $1,7 \mathrm{~m}$ para $T$. rufiventris e $2,5 \mathrm{~m}$ para T. leucomelas.

De maneira semelhante, a altura média ocupada no interior florestal variou, $H=8,1(p<0,05)$, com média de altura de 2,5 e 3,5 m para a altura de T. rufiventris e T. leucomelas, respectivamente.

A comparação intraespecífica da estratificação demonstrou que T. rufiventris apresenta diferença no estrato médio frequentado na borda, próximo a 1,4 m, no ambiente transição e interior, 2,4 e 2,5 m, respectivamente, com valor de teste $H=13,6(p>0,05)$. Não houve divergência no estrato médio ocupado para T. leucomelas.

Tratando-se da dieta das espécies, foram obtidos 26 regurgitos de T. rufiventris e 37 de T. leucomelas. A lista dos itens vegetais identificados nos regurgitos de ambas as espécies pode ser observada na Tabela 4.

A amplitude de nicho encontrada foi $B=7,86$ para $T$. rufiventris e $B=6,30$ para $T$. leucomelas. A proporção de itens de origem animal e vegetal foi similar para as duas espécies estudadas. Turdus rufiventris apresentou $84,6 \%$ de itens vegetais, sendo $15,4 \%$ da dieta composta por recursos animais, enquanto $T$. leucomelas apresentou $83,7 \%$ de itens vegetais (frutos) na dieta e $16,3 \%$ de recursos animais (invertebrados). A análise de dissimilaridade baseada apenas na presença e ausência de itens alimentares (Bray-Curtis) demonstrou baixa sobreposição de dieta $(0,32)$ evidenciando que a alta sobreposição trófica e de nicho trófico pode ser em função do consumo elevado em comum de alguns poucos itens alimentares.

\section{Discussão}

Os dados referentes à captura dos exemplares de T. rufiventris e T. leucomelas, foram semelhantes ao estudo realizado por Piratelli \& Pereira (2002), evidenciando que realmente tratam-se de espécies com taxas razoavelmente elevadas de captura em estudos com redes ornitológicas. Em um estudo da estrutura da comunidade de aves realizado no Rio Grande do Sul por Efe et al. (2007), T. rufiventris representou $6,4 \%$ das capturas tornando-se a segunda espécie mais representativa. Tratando-se especificamente da comunidade de turdídeos, T. rufiventris foi a espécie mais abundante no estudo de Gasperin \& Pizo (2009).

Os picos de captura no início da manhã e ao entardecer segue o padrão observado de forma genérica para aves (Grue et al. 1981; Mallet-Rodrigues \& Noronha 2003). A taxa de captura das aves no período da manhã e no final da tarde pode estar relacionada com a luminosidade diminuída, uma vez que os indivíduos destas espécies não conseguem detectar as redes em campo (Mallet-Rodrigues \& Noronha 2003). No entanto, o pico de atividade ao final da tarde é descrito por Sick (1997) como uma "inquietação crepuscular" em busca de alimento e um abrigo seguro para estas aves passarem a noite, evidenciando, desta maneira, a importância do fragmento como área de repouso noturno das aves.

Os picos de atividade podem também ser explicados por processos descritos por Krovetz (2000), que, ao modelar mecanismos de trade-off, observou que durante o período não reprodutivo houve, para T. merula, ganho de massa no alvorecer e antes do crepúsculo, como estratégia de minimizar o risco entre inanição e predação. Este fato é, novamente, semelhante ao observado no presente estudo.

A maior abundância nas capturas destas espécies, entre primavera e verão, deve-se principalmente ao uso do fragmento como sítio reprodutivo, fato observado durante as coletas, semelhante ao observado por Ludwig et al. (1994). No entanto, o uso do fragmento por turdídeos nas estações do outono e inverno, deve-se, em parte, à frutificação de Ligustrum lucidum e Cotoneaster franketii, já que seus frutos foram frequentemente encontrados nos regurgitos de T. rufiventris e T. leucomelas. Montaldo (1993) e, posteriormente, Scheibler \& Melo-Junior (2003) constataram a intensa frugivoria de Turdus spp. em Ligustrum spp., que de acordo com Backes \& Irgang (2004) são plantas que frutificam no Sul do Brasil entre o outono e inverno, o que também foi constatado no presente trabalho.

Cabe salientar que tais plantas são oriundas de regiões asiáticas, portanto um item alimentar descoberto pelos animais de modo semelhante ao constatado por Scheibler \& Melo-Junior (2003) e Gasperin \& Pizo (2009), que diagnosticaram a presença de espécies exóticas na dieta de turdídeos. Tal fato, em áreas periurbanas, principalmente em reservas ambientais, é de particular interesse, pois as espécies, ao se alimentarem nas proximidades acabam dispersando as sementes exóticas no interior de fragmentos florestais que servem como abrigo e habitat (Jordano et al. 2007, Instituto Horus 2009).

O grau de frugivoria foi elevado para as espécies citadas neste estudo, demonstrando certa tendência das duas espécies de Turdus, aqui estudadas em comer frutos com elevada frequência, tanto em áreas naturais como urbanizadas. Resultados semelhantes foram encontrados por Collar (2005) e Guitían et al. (2000).

A sobreposição de nicho trófico obtida neste estudo $\left(\mathrm{O}_{j k}=0,76\right)$, de acordo com Jaksic et al. (1981), pode ser considerada alta, ou seja, valores superiores a 0,67. Entretanto, Motta-Junior (2006), estudando uma comunidade de uma guilda de aves carnívoras, observaram baixa sobreposição de nicho trófico. Sendo assim, é interessante que organismos onívoros tenham alta sobreposição de seu nicho trófico. No entanto, estas comparações devem ser vistas com cautela, pois as classes de análise dos itens alimentares variam muito, sendo este método comparativo mais eficaz em estudos que sigam os mesmos critérios de classificação de itens consumidos pelos organismos.

A amplitude de nicho trófico encontrada para T. rufiventris e para T. leucomelas ( $B=7,86$ e $B=6,30$, respectivamente) é característica

Tabela 1. Médias de medidas e valores de teste " $t$ " entre Turdus rufiventris e T. leucomelas no Parque Municipal das Araucárias, Guarapuava-PR. Massa em $\mathrm{g}$, Comprimentos em mm.

Table 1. Mean values of measures and $t$-test between Turdus rufiventris and T. leucomelas in the no Parque Municipal das Araucárias, Guarapuava, Paraná State. Weight in g, Lengths in $\mathrm{mm}$.

\begin{tabular}{|c|c|c|c|c|c|c|c|}
\hline Variáveis & T. rufiventris & $\begin{array}{l}\text { Mínimo/ } \\
\text { máximo }\end{array}$ & $\mathrm{Cv} \%$ & T. leucomelas & $\begin{array}{l}\text { Mínimo/ } \\
\text { máximo }\end{array}$ & $\mathrm{Cv} \%$ & $\begin{array}{l}\text { Comparação: } \\
\text { teste " } t \text { " }\end{array}$ \\
\hline Massa & $72,8 \pm 4,3$ & $62-83$ & 5,9 & $72,4 \pm 4,0$ & $62,9-81$ & 5,6 & $t_{(106)}=0,31$ \\
\hline Comprimento total & $243,6 \pm 11,1$ & $212-270$ & 4,6 & $237,1 \pm 10,7$ & $211-256$ & 4,3 & $t_{(95)}=3,45^{*}$ \\
\hline Comprimento do bico mm) & $28,6 \pm 1,3$ & $25,1-31,5$ & 4,6 & $26,5 \pm 1,5$ & $20-30$ & 5,9 & $t_{(104)}=6,68 *$ \\
\hline Comprimento do tarso (direito) (mm) & $35,5 \pm 1,4$ & $32,0-38,7$ & 3,9 & $33,1 \pm 3,9$ & $30,7-39$ & 4,8 & $t_{(105)}=8,63 *$ \\
\hline Comprimento da asa (direita) (mm) & $114,7 \pm 4,2$ & $102-128$ & 3,7 & $114,7 \pm 3,9$ & $105-121$ & 3,4 & $t_{(105)}=0,37 *$ \\
\hline Comprimento da cauda (mm) & $98,6 \pm 5,1$ & $84-107$ & 5,1 & $95,3 \pm 4,6$ & 83-104 & 4,8 & $t_{(96)}=3,76^{*}$ \\
\hline
\end{tabular}

(*) Nível de significância $(p<0,05)$. 
de espécies com largo espectro alimentar e foram superiores ao constatado para aves florestais insetívoras por Mestre (2002). Pelo fato de turdídeos terem uma dieta mais onívora, a alta sobreposição alimentar constada neste estudo mostra que as espécies estão utilizando itens alimentares abundantes encontrados no ambiente, não gerando um padrão definido de segregação alimentar, que para Putmam (1996), não influenciará fortemente em um processo de exclusão competitiva. Por outro lado, observando a lista de itens consumidos por T. rufiventris e T. leucomelas, percebeu-se o consumo diferenciado de alguns itens, exclusivos de uma ou outra espécie, levando à hipóteses mais específicas, sobre a relação entre recursos principais de cada espécie e a altura em que é obtido, como forma de influenciar o estrato florestal frequentado, mas que não pode ser testado neste trabalho em específico.

Tratando-se da partilha de habitat, não ficou claro um padrão que permitisse inferir que as espécies ocupassem estratos florestais diferenciados. No entanto, houve uma tendência do aumento da altura média ocupada no interior em relação à borda florestal pelas espécies, de modo que T. leucomelas não apresentou divergência no estrato florestal frequentado. Por sua vez, T. rufiventris ocupou um estrato

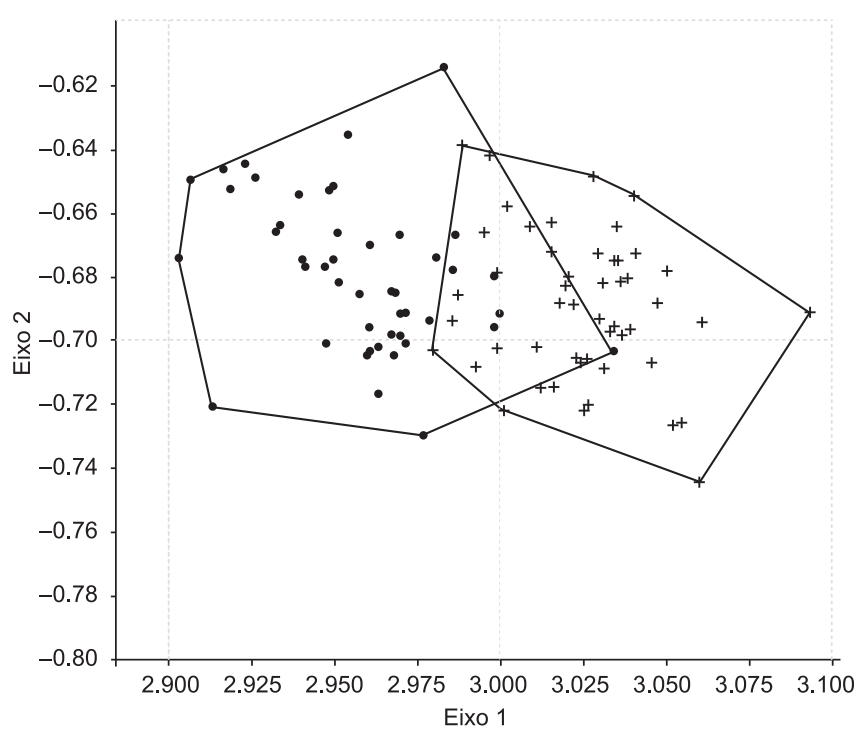

Figura 4. Agrupamento para sete caracteres morfológicos provenientes de MANOVA/CVA. Legenda: (•) Turdus leucomelas e (+) T. rufiventris.

Figure 4. Clustering for seven morphological characters from MANOVA/CVA. Legend: $(\bullet)$ Turdus leucomelas and (+) T. rufiventris. relativamente mais baixo na borda florestal em face ao observado no interior florestal. Padrões de interação comportamental não foram o foco deste estudo, mas podem, em parte, explicar a coexistência entre tais espécies congenéricas.

Dados que demonstram o aspecto vertical ocupado por Turdus foram obtidos por Dickson \& Noble (1978), que constataram que T. migratorius é uma espécie amplamente distribuída dentro da estrutura florestal, e pode ocupar desde o solo até o dossel florestal, indicando que espécies de Turdus podem ter ampla faixa de ocupação vertical de habitat. De fato, segundo Pearson (1971), a estrutura da vegetação é fator fundamental na estratificação da comunidade de aves, neste sentido a densidade da vegetação interfere de alguma forma na ocupação do ambiente. Logo, a comunidade pode variar de acordo com a estrutura florestal, uma vez que os estratos sub-bosque e dossel possuem padrões de disponibilidade de frutos e artrópodes diferenciados (Pearson 1971). Geralmente, o dossel está intimamente associado com a produção de frutos devido à maior incidência solar, enquanto o sub-bosque é caracterizado pela abundância de artrópodes ligados à decomposição do folhiço (Develey \& Peres 2000). Desta forma, a abundância de artrópodes junto a estratos mais baixos, favorece a exploração do solo com a busca de presas vivas, enquanto no interior da floresta, provavelmente, a disponibilidade de frutos e a arquitetura do ambiente influenciam no estrato ocupado.

A ocupação dos ambientes borda florestal, transição ou interior não variou de forma significativa. Dados semelhantes foram obtidos por Hatchwell et al. (1996), onde ficou constatado que a estrutura do habitat não teve nenhum efeito significativo no sucesso reprodutivo de T. merula.

Quanto à comparação morfológica, embora os indivíduos sejam muito parecidos, alguns caracteres variaram, permitindo um mínimo de divergência morfológica, resultado já previsto em teoria para a coexistência (MacArthur \& Levins 1967). Para Schoener (1974) o tamanho e a forma do bico são relacionados frequentemente com o tipo e o tamanho da presa apanhada e variações na forma do bico estão relacionadas com técnicas de forrageamento. Neste sentido, observou-se que a variação para tamanho de bico pode permitir uma diferenciação na dieta. Esta variação, embora pequena, pode levar a uma leve distinção dos itens alimentares, como observado na análise da dieta, já que o tamanho das asas não variou, refletindo em formas convergentes de ocupação e exploração do ambiente. Para Podos (2001) a massa e tamanho do corpo igualmente evoluem como uma adaptação direta aos ambientes divergentes, e como um efeito indireto correlacionado a adaptação do bico, já que este responde pela apropriação do recurso.

Tabela 2. Análise de componentes principais (ACP) para quatro medidas obtidas a partir do bico de Turdus rufiventris e T. leucomelas no Parque Municipal das Araucárias, Guarapuava, Paraná.

Table 2. Principal component analysis (PCA) to four measurements obtained from the beak of Turdus rufiventris and T. leucomelas in the Parque Municipal das Araucárias, Guarapuava, Paraná State.

\begin{tabular}{lcccc}
\hline \multicolumn{1}{c}{ Parâmetros } & Componente 1 & Componente 2 & Componente 3 & Componente 4 \\
\hline Autovalores & 19,001 & 0,9553 & 0,7813 & 0,3632 \\
$\quad$ Porcentagem & 47,5 & 23,88 & 19,53 & 9,809 \\
Porcentagem acumulada & 47,5 & 71,39 & 90,92 & 100 \\
Auto vetores & - & - & - & - \\
$\quad$ Comprimento total do bico & 0,63 & $-0,14$ & $-0,11$ & $-0,75$ \\
Comprimento narina/ponta do bico & 0,57 & $-0,25$ & $-0,5$ & 0,6 \\
Largura do bico na base & 0,23 & 0,96 & $-0,17$ & 0,04 \\
Altura do bico em relação à base & 0,47 & 0,03 & 0,84 & 0,27 \\
\hline
\end{tabular}


Vogel, H.F. et al.
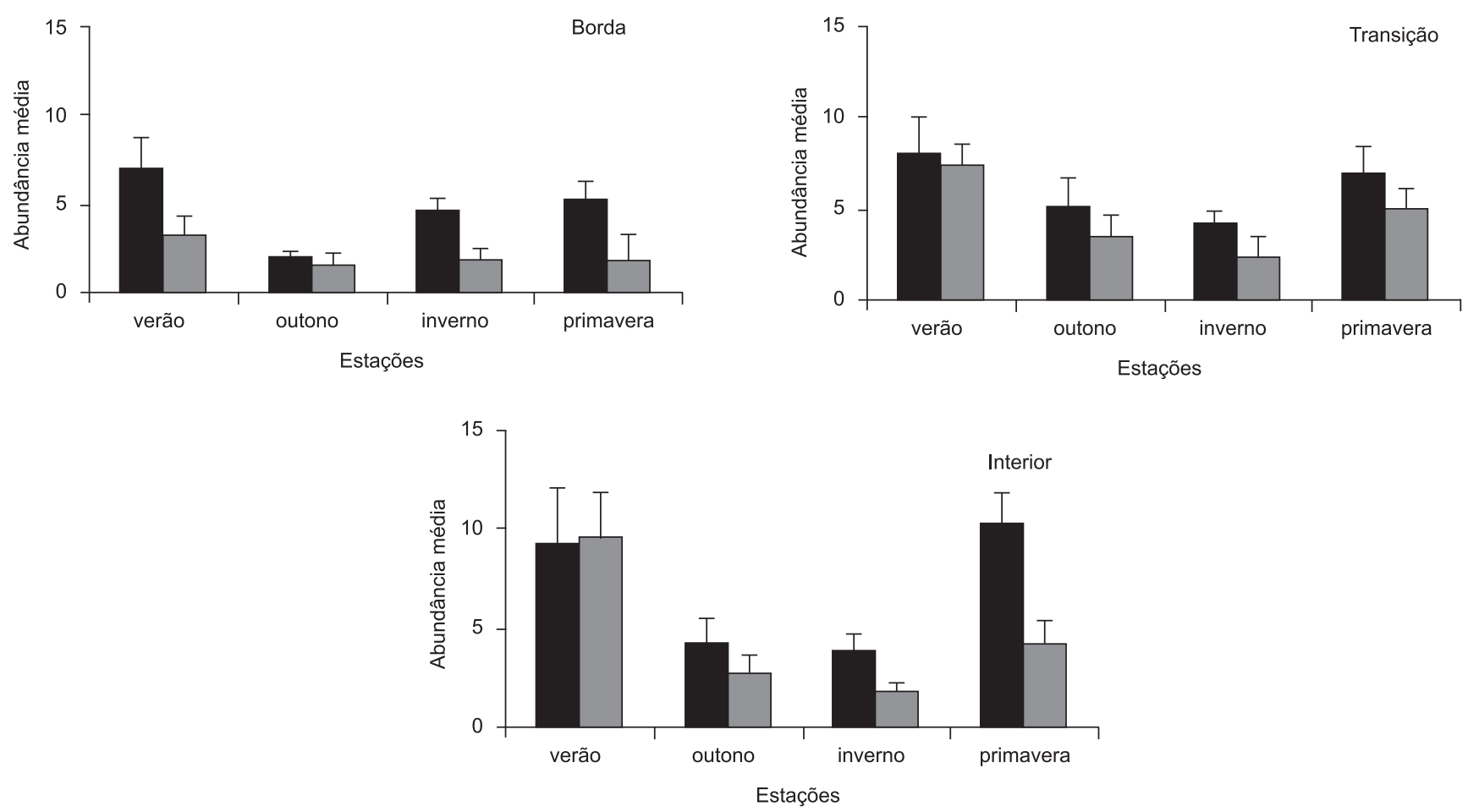

T. rufiventris

T. leucomelas

Figura 5. Dinâmica de abundância média ao longo das estações de Turdus rufiventris e T. leucomelas no Parque Municipal das Araucárias.

Figure 5. Average abundance dynamics during the seasons for Turdus rufiventris and T. leucomelas at Parque Municipal das Araucárias.

Tabela 3. Estatística descritiva sobre a exploração vertical do estrato florestal para Turdus rufiventris e T. leucomelas no Parque Municipal das Araucárias. Table 3. Descriptive statistics on the exploitation of vertical forest stratum by Turdus rufiventris and T. leucomelas in Parque Municipal das Araucárias.

\begin{tabular}{|c|c|c|c|c|c|c|}
\hline & \multicolumn{3}{|c|}{ T. rufiventris } & \multicolumn{3}{|c|}{ T. leucomelas } \\
\hline & Borda & Transição & Interior & Borda & Transição & Interior \\
\hline Tamanho da amostra & 131 & 146 & 172 & 54 & 118 & 115 \\
\hline Mínimo & 0,0 & 0,0 & 0,0 & 0,0 & 0,0 & 0,0 \\
\hline Máximo & 9,0 & 9,0 & 12,0 & 9,0 & 10,0 & 15,0 \\
\hline Amplitude total & 9,0 & 9,0 & 12,0 & 9,0 & 10,0 & 15,0 \\
\hline Mediana & 0,0 & 1,0 & 1,0 & 2,0 & 2,0 & 3,0 \\
\hline Primeiro quartil (25\%) & 0,0 & 0,0 & 0,0 & 1,0 & 0,0 & 0,0 \\
\hline Terceiro quartil (75\%) & 2,0 & 4,0 & 4,0 & 4,0 & 4,0 & 6,0 \\
\hline Média aritmética & 1,71 & 2,57 & 2,54 & 2,56 & 2,67 & 3,52 \\
\hline Variância & 4,08 & 6,95 & 7,49 & 4,70 & 6,11 & 10,23 \\
\hline Desvio padrão & 2,02 & 2,63 & 2,73 & 2,16 & 2,47 & 3,19 \\
\hline Erro padrão & 0,17 & 0,21 & 0,20 & 0,29 & 0,22 & 0,29 \\
\hline Coeficiente de variação (\%) & 156,90 & 114,29 & 114,00 & 88,08 & 99,93 & 95,30 \\
\hline
\end{tabular}

A forma do bico entre T. rufiventris e T. leucomelas possui características semelhantes à espécies onívoras da família Tyrannidae (Fitzpatrick 1985, Sick 1997). De certa maneira, tal formato confere uma vantagem ecológica na exploração ambiental, pois a onivoria é citada por Willis (1979) como suprimento contra flutuações ambientais.

Variações no tamanho e na forma da asa estão associadas com o modo de exploração do ambiente (Fitzpatrick 1985). Evans et al. (2009) constataram que populações urbanas e rurais de T. merula exibiram diferenças morfológicas significativas para a forma das asas, sendo que o valor e o sentido da diferenciação eram dependentes do local. Deste modo, a morfologia da asa pode variar de acordo com características ambientais, embora este fato não tenha sido observado para o tamanho da asa no presente trabalho.

Neste estudo, foi observado que as variáveis mensuradas tiveram maior amplitude em $T$. rufiventris, tanto para as medidas de comprimento das estruturas, quanto para a massa e amplitude de nicho trófico. Isto pode refletir uma maior plasticidade fenotípica destes 
Tabela 4. Freqüência percentual (F\%) de itens consumidos por Turdus rufiventris $(T r ; \mathrm{n}=26)$ e Turdus leucomelas $(T l ; \mathrm{n}=37)$.

Table 4. Percentage frequency (F\%) of items consumed by Turdus rufiventris $(\operatorname{Tr} ; \mathrm{n}=26)$ and Turdus leucomelas $(T l ; \mathrm{n}=37)$.

\begin{tabular}{|c|c|c|c|}
\hline Famílias & Espécies & $\operatorname{Tr}(\mathbf{F} \%)$ & $\mathrm{Tl}(\mathrm{F} \%)$ \\
\hline Adoxaceae & Sambucus nigra $\mathrm{L}$. & 4,5 & 0 \\
\hline Anacardiaceae & Schinus terebinthifolius Raddi & 4,5 & 0 \\
\hline Aquifoliaceae & Ilex paraguariensis St. Hil. & 0 & 6,4 \\
\hline Berberidaceae & Berberis laurina Billb. & 4,5 & 0 \\
\hline Celastraceae & Maytenus ilicifolia Mart. Ex. Reiss & 4,5 & 0 \\
\hline Flaucortiaceae & Caseria decandra Jacq. & 0 & 6,4 \\
\hline Lauraceae & Nectandra megapotamica (Spreng.) Mez & 18,18 & 3,2 \\
\hline Magnoleaceae & *Magnolia grandiflora $\mathrm{L}$ & 0 & 6,4 \\
\hline Melastomataceae & Miconia cinerascens Miq. & 4,5 & 0 \\
\hline Melastomataceae & Miconia cf. cabussu Hoehne & 0 & 6,4 \\
\hline Myrsinaceae & Myrsine ferruginea Spr. & 9,09 & 0 \\
\hline Myrtaceae & Camponesia xanthocarpa Berg & 0 & 3,2 \\
\hline Oleaceae & *Ligustrum lucidum W.T.Aiton & 9,09 & 23 \\
\hline Rosaceae & *Cotoneaster franketii Bois & 27,27 & 35 \\
\hline Rutaceae & Zanthoxylum rhoifolium Lam. & 0 & 3,2 \\
\hline Sapindaceae & Allophylus edulis (St. Hil.) Radlk & 4,5 & 0 \\
\hline Sapindaceae & Symplocos uniflora Benth. & 9,09 & 0 \\
\hline Não identificada & Folhas & 0 & 3,2 \\
\hline Não identificada & Sementes & 0 & 3,2 \\
\hline Total: 15 famílias & 17 espécies & $100 \%$ & $100 \%$ \\
\hline \multicolumn{4}{|c|}{ Itens animais na dieta } \\
\hline \multicolumn{4}{|l|}{ Categoria } \\
\hline Gastropoda e Oligocheta & & 100 & 83 \\
\hline Arthropoda & & 0 & 17 \\
\hline Total: & & $100 \%$ & $100 \%$ \\
\hline Itens de origem vegetal & & $84,60 \%$ & $83,70 \%$ \\
\hline Itens de origem animal & & $15,40 \%$ & $16,30 \%$ \\
\hline
\end{tabular}

(*) Espécies exóticas da flora local.

caracteres, o que, de acordo com Miner et al. (2005), pode ser uma provável resposta adaptativa de modo que o tipo de plasticidade (e.g. morfológica) pode conferir maiores vantagens frente à exploração de recursos ambientais.

\section{Considerações Finais}

Apesar de muito semelhantes morfologicamente, T. rufiventris e T. leucomelas divergem em um mínimo possível, principalmente quanto às variáveis de massa, comprimento total, comprimento do bico, da cauda e tamanho de tarso. Os dados indicam que T. rufiventris é uma espécie mais plástica com maiores extremos em suas estruturas, o que evolutivamente acredita-se conferir vantagens adaptativas, principalmente na exploração de nicho.

Quanto à dieta, houve grande sobreposição trófica e sobreposição de nicho trófico, sendo a amplitude de nicho maior para T. rufiventris, possivelmente associada à plasticidade fenotípica da espécie. Quanto à utilização dos recursos alimentares, as espécies, aparentemente, consomem uma proporção elevada de alguns poucos recursos, possivelmente os mais abundantes. Adicionalmente, consomem alguns itens ligeiramente distintos entre si, de modo que processos de competição interespecífica por recursos alimentares não ficaram evidentes.

A abundância entre as espécies por estação e ambiente não variou de forma estatisticamente significante, e provavelmente foi influenciada pela oferta sazonal de alimento, ao ponto de ter sua variação na abundância influenciada de maneira correlacionada.

Quanto à ocupação dos estratos, embora não significativa para a maioria dos efeitos testados, houve uma tendência à ocupação de estratos florestais superiores por T. leucomelas, enquanto $T$. rufiventris tendeu a diminuir sua altura de forrageamento na borda e interior florestal. O horário de atividade das duas espécies foi similar, não indicando que ocorra um padrão de segregação ecológica baseado em picos de atividade.

\section{Agradecimentos}

Somos gratos a José Flavio Cândido Junior, Marcia Czulik e Gustavo Sene Silva, pela leitura crítica do manuscrito e valiosas sugestões; aos revisores da revista Biota Neotropical; ao IBAMA pela licença de pesquisa científica $n^{\circ} 16053-1$ e ao CEMAVE/SNA por conceder autorização para anilhamento através do processo n 3031-1 e pelas anilhas metálicas cedidas. Agradecemos também à Secretaria de Meio Ambiente e Desenvolvimento Florestal de Guarapuava pela autorização de pesquisa no Parque Municipal das Araucárias, e ao Conselho de Desenvolvimento Científico e Tecnológico (CNPq) por fornecer apoio financeiro a CHZ (proc. 306066/2009-2 e a Coordenação de Aperfeiçoamento de Pessoal de Nível Superior (CAPES) pela bolsa concedida à HFV. 


\section{Referências Bibliográfias}

AURICCHIO, P. 2001. Aves. In Técnicas de Coleta e Preparação de Vertebrados (P. Auricchio \& E.M.G. Salomão, orgs.). FAPESP, São Paulo, p.127-148.

BACKES, P. \& IRGANG, B.E. 2004. Árvores cultivadas no sul do Brasil. Paisagens do Sul, Porto Alegre, 204p.

BIBBY, C.J., BURGESS, N.D. \& HILL, D.A. 1993. Bird census techniques. Academic Press, London, 257p.

BOEV, Z. 2001. Late pleistocene and holocene avian finds from the Vicinity of the Lakatnki R/W Station (W Bulgária). In. Earth and Man National Museum Associations of Environment and Cultural Heritage in Karst. (P.S. Delchev, A. Shanov \& A. Benderev, orgs.). Sofia, Karst, p.107-112.

BONNEVIE, B.T. 2005. The biology of suburban olive thrushs (Turdus olivaceus olivaceus) in the Eastern Cape, Soufh Africa. Masters thesis, Rhodes University.

BURFIELD, I.J.M. \& BROOKE, D.E.L. 2005. The decline of the Ring Ouzel Turdus torquatus in BritaIn evidence from bird observatory data. Ring. Migrat. 22:199-204.

CENTRO DE PESQUISA PARA A CONSERVAÇÃO DE AVES SILVESTRES - CEMAVE. 1994. Manual de anilhamento de aves silvestre. Instituto Brasileiro do Meio Ambiente e Recursos Renováveis, Brasília, 146p.

COLLAR, N.J. 2005. Family Turdidae (thrushes). In Handbook of the birds of the world. (J. Del Hoyo., A Elliot \& D.A. Christie, orgs.). Lynx Edicions, Barcelona, 729p.

COMITÊ BRASILEIRO DE REGISTROS ORNITOLÓGICOS - CBRO. 2009. Listas das aves do Brasil. Disponível em http://www.cbro.org.br (último acesso em 02/05/2010).

CORDEIRO, J. \& RODRIGUES, W.A. 2005. Levantamento Florístico de Plantas Exóticas do Parque Municipal das Araucárias Guarapuava PR. In Anais do I Simpósio Brasileiro De Espécies Exóticas Invasoras, 2005. MMA, Brasília.

CORDEIRO, J. \& RODRIGUES, W.A. 2007. Caracterização fitossociológica de um Remanescente de floresta Ombrófila Mista em Guarapuava, PR. Rev. Árvore 31(3):545-554. http://dx.doi.org/10.1590/S010067622007000300020

DEVELEY, P.F. \& PERES, C.A. 2000. Resource seasonality and the structure of mixed species bird flocks in a coastal Atlantic forest of southeastern Brazil. J. Trop. Ecol. 16(1):33-53. http://dx.doi.org/10.1017/ S0266467400001255

DICKSON, J.G. \& NOBLE, R.E. 1978. Vertical distribution of birds in Louiziania Bottomland hardwood forest. Wilson Bull. 90(1):19-30.

EFE, M.A., OLIVEIRA, A.C., KOCH, M., FLÔRES, J.M. \& SCHERER, S.B. 2007. Avifauna da Área de Proteção Ambiental do Ibirapuitã, Rio Grande do Sul, Brasil. Ornithologia. 2(1):14-24.

EVANS, K.L., GASTON, K.J., SHARP, S.P., MCGOWAN, A. \& HATCHWELL, B.J.S. 2009. The effect of urbanization on avian morphology and latitudinal gradients in body size. Oikos 118(2):251-259. http://dx.doi.org/10.1111/j.1600-0706.2008.17092.x

FITZPATRICK, J.W. 1985. Form, foraging behavior, and adaptive radiation in the Tyrannidae. Ornithol. Monogr. 36:447-470.

GASPERIN, G. \& PIZO, M.A. 2009. Frugivory and habitat use by thrushes (Turdus spp.) in a suburban area in south Brazil. Urban Ecosyst. 12:425-436. http://dx.doi.org/10.1007/s11252-009-0090-2

GONÇALVES, M.L. \& FONTANA, C.S. 2009. Relação entre a idade e o padrão de coloração da plumagem em sabiá-laranjeira, Turdus rufiventris Vieillot, 1818. In X Salão de Iniciação Científica, 2009. PUCRS, Porto Alegre.

GOTELLI, N.J. \& ENTSMINGER, G.L. 2004. EcoSim: Null models software for ecology. Version 7.0. www.garyentsminger.com/ecosim/index.htm (último acesso em 12/12/2009).

GREGÓRIE, A., STÉPHANE, G., DRÉANO, N. \& FAIVRE, B. 2003. Nest predation in Blackbirds (Turdus merula) and the influence of nest characteristics. Ornis Fenn. 80(1):01-10.
GRUE, C.E., BALDA, R.P. \& JOHNSON, C.D. 1981. Diurnal activity patterns and population estimates of breeding birds within a disturbed and undisturbed desert-scrub community. Stud. Avian Biol. 6:287-291.

GUITÍAN, J., GUITÍAN, P., MUNILLA, I., BERMEJO, T., LARRINGA, A.R., NAVARRO, L. \& LÓPEZ, B. 2000. Zorzales, espinos y serbales: un estudio sobre el consumo de frutos silvestres de las aves migratórias en la costa occidental europea. Universidade de Santiago, Compostela, 292 p.

HAMMER, O., HARPER, D.A.T. \& RYAN, P.D. 2003. PAST: Paleontological Statistics Software Package for Education and Data Analysis. Palaeontol. Elect. 4.

HATCHWELL, B.J., CHAMBERLAIN, D.E., \& PERRINS, C.M. 1996. The reproductive success of Blackbirds Turdus merula in relation to habitat structure and choice of nest site. Ibis 138(2):256-262. http://dx.doi. org/10.1111/j.1474-919X.1996.tb04337.x

HESPENHEIDE, H.A. 1973. Ecological inferences from morphological data. Annu. Rev. Ecol. Syst. 4:212-229. http://dx.doi.org/10.1146/annurev. es.04.110173.001241

HOGSTAD, O. 2004. Nest defense strategies in the Fieldfare Turdus pilaris: the responses on an avian and a mammalian predator. Ardea 92(1):79-84.

HORN, H.S. 1966. Measurement of "overlap" in comparative ecological studies. Am. Nat. 100:419-424. http://dx.doi.org/10.1086/282436

HUTCHINSON, G.E. 1959. Homage to Santa Rosalia or Why Are There So Many Kinds of Animals. Am. Nat. 93(870):145-159. http://dx.doi. org/10.1086/282070

INSTITUTO HORUS. 2009. Lista oficial das espécies invasoras do Brasil. www.institutohorus.org.br (último acesso em 02/06/2009).

JAKSIC, F.M., GREENE, H. \& YÁNEZ, E.J.L. 1981. The guild structure of a community of predatory vertebrates in central Chile. Oecologia 49(1):21-28. http://dx.doi.org/10.1007/BF00376893

JORDANO, P., GARCIA, C., GODOY, J.A. \& GARCÍA-CASTAÑO, J.L. 2007. Differential contribution of frugivores to complex seed dispersal patterns. Proc. Natl. Acad. Sci. 104:3278-3282. PMid:17360638. PMCid:1805555. http://dx.doi.org/10.1073/pnas.0606793104

KREBS, C.J. 1985. Ecology: The Experimental Analysis of Distribution and Abundance. Harper and Row, New York, 800p.

KREBS, C.J. 1989. Ecological methodology. Harper Collins Publishers, New York, 654p.

KROVETZ, R. 2000. Viewing morphology as an inference process. Artif. Intell. 118:277-294. http://dx.doi.org/10.1016/S0004-3702(99)00101-0

KRÜGEL, M. M. \& ANJOS, L. 2000. Bird communities in Forest remnants in the city of Maringá, Paraná State, Southern Brazil. Ornitol. Neotrop. 11(4):315-330,

LEVINS, R. 1968. Evolution in changing environments. University Press, New Jersey, 120p.

LOSSOS, J.B. 2000. Ecological character displacement and the study of adaptation. Proc. Natl. Acad. Sci. 97(8):4106-4111

LUDWIG, E., VANICSEK, L., TOROK, J. \& CSORGO, T. 1994. The effect of nest height on the seasonal pattern of breeding success in Blackbirds Turdus merula. Ardea 83:411-418.

MacARTHUR, R. \& LEVINS, R. 1967. The limiting similarity, convergence, and divergence of coexisting species. Am. Nat. 101(921):377-385. http://dx.doi.org/10.1086/282505

MALLET-RODRIGUES, F. \& NORONHA, M.L.M. 2003. Variação na taxa de captura de passeriformes em um trecho de mata atlântica de encosta, no sudeste do Brasil Ararajuba 11(1):111-118.

MACHADO, C.G. 1999. Composição e estrutura de bandos mistos de aves na Mata Atlântica do alto da Serra do Paranapiacaba. Rev. Bras. Biol. 59(1):75-85.

MAY, R.M. 1975. Patterns of species abundances. In Ecology and evolutions of communities (M.L. Cody \& J.M. Diamond, orgs.). Belknap Press, Cambridge, p. $81-120$.

MESTRE, L.A.M. 2002. Dieta de aves insetívoras terrestres e a disponibilidade de presas em fragmentos florestais Amazônicos. Dissertação de Mestrado, Universidade Federal de São Carlos, São Carlos. 
MINER, B.G., SULTAN, S.E., MORGAN, S.G., PADILLA, D.K. \& REYLEA, R.A. 2005. Ecological consequences of phenotypic plasticity. Ecol. Evol. 20(12):685-692. http://dx.doi.org/10.1016/j.tree.2005.08.002

MONTALDO, N.H. 1993. Dispersión por aves y êxito reproductivo dos espécies de Ligustrum (Oleaceae) em um relicto de selva subtropical en la Argentina. Rev. Chil. Hist. Nat. 66:75-85.

MOTTA-JUNIOR, J.C. 2006. Relações tróficas entre cinco Strigiformes simpátricas na região central do Estado de São Paulo, Brasil. Ararajuba. 14(4):359-377.

PEARSON, D.L. 1971. Vertical stratification of birds in a tropical dry Forest. Condor. 73:46-55. http://dx.doi.org/10.2307/1366123

PIANKA, E.R. 1967. On lizard species diversity: North American flatland deserts. Ecology. 48:333-351. http://dx.doi.org/10.2307/1932670

PIANKA, E.R. 1973. The structure of lizard communities. Annu. Rev. Ecol. Syst. 4:53-74. http://dx.doi.org/10.1146/annurev.es.04.110173.000413

PIANKA, E.R. 1982. Ecologia evolutiva. Omega, Barcelona, 365p.

PIRATELLI, A. \& PEREIRA, E.R.M. 2002. Dieta de aves na região leste de Mato Grosso do Sul, Brasil. Ararajuba 10(2):131-139.

PODOS, J. 2001. Correlated evolution of morphology and vocal signal structure in Darwin's finches. Nature 409:185-188. http://dx.doi. org/10.1038/35051570

POULIN, B., LEFEBVRE, G. \& MCNEIL, R. 1994. Effect end efficiency of tartar emeticin determining the diet of tropical land birds. Condor 96:98-104. http://dx.doi.org/10.2307/1369067

PUTMAM, R.J. 1996. Community ecology. Chapman \& Hall, London.

REICHARD, S.H., CHALKER-SCOTT, L. \& BUCHANAN, E.S. 2001. Interactions among non-native plants and birds. In Avian ecology and conservation in an urbanizing world (J.M. Marzluff, R. Bowman \& D.R. Donnelly, orgs.). Kluwer Academic, Dordrecht, p.179-223.
ROBINSON, S.K. \& HOLMES, R.T. 1982. Foraging behavior of forest birds: the relationships among search tactics, diet, and habitat structure. Ecology 63(6):1918-1931. http://dx.doi.org/10.2307/1940130

RODRIGUES, E. 1998. Efeito de bordas em fragmentos de floresta. Cad. Biodivers. 1(2):1-5.

ROUGHGARDEN, J. \& DIAMOND, J.M. 1986. Overview: The role of species interactions in community ecology. In Community Ecology (J.M. Diamond \& J. Case, orgs.). Harper \& Row, New York.

SCHEIBLER, D.R. \& MELO-JUNIOR, T.A. 2003. Frugívoria por aves em duas espécies exóticas de Ligustrum (Oleaceae) no Brasil. Ararajuba 11(1):89-91.

SCHOENER, T.W. 1974. Resource partitioning in ecological communities. Science 185:27-39. PMid:17779277. http://dx.doi.org/10.1126/ science.185.4145.27

SICK, H. 1997. Ornitologia brasileira. Nova Fronteira, Rio de Janeiro, 862p.

SIGRIST, T. 2006. Aves do Brasil. uma visão artística. Fosfértil, São Paulo, 672p.

STRAUBE, F.C. \& BIANCONI, G.V. 2003. Sobre a grandeza e unidade utilizada para estimar esforço de captura com utilização de redes-de-neblina. Divul. Mus. Cienc. Tecnol. 2:52-53.

TOMAZ, V.C. \& ALVES, M.A.S. 2007. Estratificação vertical e dieta de Turdus albicollis (sabiá-de-coleira) e Platycichla flavipes (sabiá-una) em uma área de mata atlântica da Ilha Grande, RJ. In Anais do VIII Congresso de Ecologia do Brasil, 2007. SBE, Caxambu.

WILLIS, E.O. 1979. The composition of avian communities in remanescet woodlots in southern Brazil. Pap. Avulsos Zool. 33(1):01-25.

ZACA, W. 2000. Composição da Avifauna de um Fragmento Florestal de Altitude no Município de Atibaia (SP). Acta Biol. Leopoldensia 27:175-182. 